\title{
Thermal state analysis of energy saving structures of cast-in-place lightweight aggregate concrete walls
}

\author{
Nikolay Tsvetkov ${ }^{1, *}$, Andrei Khutornoi ${ }^{1}$, Alexandr Kozlobrodov ${ }^{1}$, Anna Kolesnikova ${ }^{1}$, \\ Elena Ivanova ${ }^{1}$, and Artem Golovko ${ }^{1}$ \\ ${ }^{1}$ Tomsk State University of Architecture and Building, 634003 Tomsk, Russia
}

\begin{abstract}
The purpose of this paper is numerical study on the impact of location of cylindrical fillers made of insulating material on the thermal state and thermal protection properties of the corner fragment of cast-in-place lightweight aggregate external wall. Solution of spatial thermal conductivity problem was obtained and the effect of low-thermal-conductivity fillers location inside the corner fragment of a wall was analyzed using the software complex Ansys. The nature of temperature fields distribution was determined both inside the wall and in the inner corner of the structure. The method for temperature increase in the inner corner is suggested and its quantitative evaluation is performed. The effect of thermophysical and geometrical parameters of wall materials on its thermal insulation properties is analyzed.
\end{abstract}

\section{Introduction}

Effective use of energy sources in various branches of national economy is an important strategic task for Russia. In Russian construction industry, 23\% of total energy consumed is spent on provision of heating energy to buildings and structures [1-3]. Heating energy loss through external walls in buildings can reach up to $45 \%$ depending on their structural peculiarities [4-5]. In this regard, design of new structures with improved thermal insulation properties and justification of the possibility of their effective use is a relevant task.

The issue of construction of buildings that satisfy ever increasing standard requirements regarding energy efficiency is directly connected with the level of thermal protection of external walls, which is greatly dependent on whether effective insulation is installed in the wall structure. External walls are divided into 3 types with regard to location of insulation: walls with insulation located on external surface of the wall; walls with insulation located on inner surface of the wall; and walls with insulation located inside the wall [6].

In the research [7] two types of structures with the same thickness of insulation layer are analyzed: a conventional multilayer facade and a hinged ventilated facade. As the result of the analysis hinged ventilated facade was found to be the most energy efficient in the climate conditions of Saint Petersburg. The works[8-9] suggest the new system of facade insulation by panels with ventilated channels; they also present analysis results for buildings with brick

*Corresponding author: nac.tsuab@yandex.ru 
external walls and prove high efficiency of using the suggested system in Siberian climate conditions.

The research [10] provides analysis and development of a numerical model for simulation of unstable thermal behavior, both on the surface and in the corner joint of an external wall; consequently, this enables to define a building's demand in heating energy. Also, in [11] the authors present quantitative assessment of heat transfer through the external walls in the corner fragment.

Since external corner in the most heat-stressed area of the envelope of a building, the research [12] presents the model for calculating heat transfer in the external corner area. As the result of the simulation, the influence of thickness and location of insulation layers on the temperature field was determined; methods for reducing and even eliminating the impact of a heat-stressed element were developed.

In [13], the authors suggest a structural scheme for a cast-in-place external lightweight aggregate concrete wall with regularly located vertical vapor-proof compound formworks with efficient insulation [14]. Numerical and experimental studies on thermal protection properties of a wall were performed. However, regularities of fields distribution on the wall surface considerably differ from such regularities in wall corners [15]. The temperature of internal corner surface, as a rule, is lower than that of the wall surface, which can lead to condensate formation. For that reason, investigation of thermal state peculiarities of such heatstressed elements of building envelopes, including corner of a building studied in the paper, shall be considered new and have remarkable practical importance. The main contribution of the paper to the previous research in the field consists in the advanced consideration of physics of thermal processes in multilayer structures with heat-stressed elements and in defining new regularities and relations that allow evaluating the impact of geometrical factors and heat transfer conditions on thermal state of a building envelope with regard to its energy efficiency.

Thus, the purpose of this paper is mathematical modeling and numerical study of thermal state of a corner fragment of a cast-in-place external lightweight aggregate concrete wall with various locations of insulating fillers inside the structure, as well as assessment of the effect of cable embedded in the corner.

\section{Physico-mathematical statement of a problem}

Research of thermal protection properties of a cast-in-place lightweight aggregate concrete wall is performed for a corner fragment with various locations of insulating fillers inside the structure (Fig. 1).

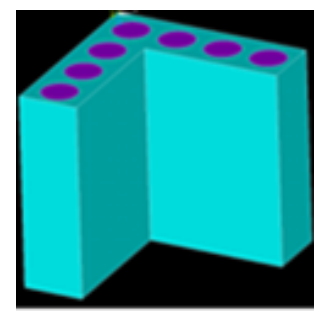

a)

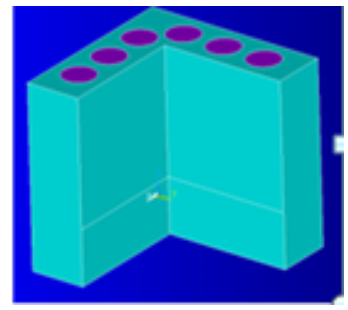

b)

Fig. 1. Structures of external wall under study: $a$-structure of a wall with a vertical insulating filler located on the line that connects vertices of internal and external angles (hereinafter referred to as variant 1$) ; b$-structure of a wall without a vertical insulating filler on the line that connects vertices of internal and external angles (hereinafter referred to as variant 2). 
For mathematical problem statement, size parameters of envelope structures and their thermophysical characteristics are considered as given, generally, they may depend on the temperature. Geometrical parameters of the fragments are as follows: wall thickness $\delta_{\mathrm{c}}=$ $0.5 \mathrm{~m}$, fillers diameter $d=0.3 \mathrm{~m}$. Thermal conductivity coefficients for lightweight aggregate concrete $\lambda=0.41 \mathrm{~W} /\left(\mathrm{m}^{\circ}{ }^{\circ} \mathrm{C}\right)$, for insulating fillers made of polyurethane foam $\lambda=0.04$ $\mathrm{W} /\left(\mathrm{m} \cdot{ }^{\circ} \mathrm{C}\right)$. The outdoor temperature $t_{\text {otd }}$ and indoor temperature $t_{\text {ind }}$ are set, as well as heat transfer coefficients for external and internal surfaces. The indoor and outdoor temperature values are +22 and $-40{ }^{\circ} \mathrm{C}$, and heat transfer coefficients for external and internal surfaces, respectively, are $\alpha_{\text {otd }}=23 \mathrm{~W} /\left(\mathrm{m}^{2} \cdot{ }^{\circ} \mathrm{C}\right)$ and $\alpha_{\text {ind }}=8.7 \mathrm{~W} /\left(\mathrm{m}^{2} \cdot{ }^{\circ} \mathrm{C}\right)$.

Unstable spatial transfer occurring in the structural fragment under study is described in Cartesian coordinate system as a system of nonlinear stationary three-dimensional equations for thermal conductivity [12], their number being equal to the total number of constituent elements $(n)$ :

$$
\frac{\partial t_{i}}{\partial \tau}=\frac{\partial}{\partial x}\left(\lambda_{x, i} \frac{\partial t_{i}}{\partial x}\right)+\frac{\partial}{\partial y}\left(\lambda_{y, i} \frac{\partial t_{i}}{\partial y}\right)+\frac{\partial}{\partial z}\left(\lambda_{z, i} \frac{\partial t_{i}}{\partial z}\right),
$$

where $i=1, \ldots, n$ with corresponding initial and boundary conditions.

For initial conditions are taken temperature field that corresponds to the solution of the stationary problem, and uniform temperature field or temperature for each element (layer) of a structure.

$$
\left.t_{i}\right|_{\tau=0}=t_{0}(x, y, z) ; i=1, \ldots, n ; x, y, z \in \Omega,
$$

where $\Omega$ - closed region of variation of independent spatial variables.

Boundary conditions for all internal and external surfaces are the boundary conditions of type III which account heat exchange between these surfaces and the environment; for example, for internal surfaces such conditions can be put in the following form:

$$
-\left.\lambda_{n, m} \frac{\partial t_{m}}{\partial n}\right|_{n=0}=\alpha_{i n t}\left(t_{i n t}-t_{\text {surf }, m}\right),
$$

where $n$ - the direction of normal to the corresponding surface; $m$-number of the element that contacts with indoor air; $\lambda_{n, m}-$ thermal conductivity coefficient of the material of this element; $t_{\text {int }}, t_{\text {surf }, m}$ - temperatures of internal air and the contacting surface, respectively.

In the interface of two adjacent elements the boundary conditions of type IV are established, according to which the temperatures and the heat flows rate shall be equal:

$$
\begin{aligned}
& \left.t_{\text {bound.,m }}\right|_{\text {bound. }}=\left.t_{\text {bound.,m+1 }}\right|_{\text {bound. }} ; \\
& -\lambda_{n, m} \frac{\partial t_{m}}{\partial n}=-\left.\lambda_{n, m+1} \frac{\partial t_{m+1}}{\partial n}\right|_{\text {bound. }} .
\end{aligned}
$$

For all edges of the structure symmetry condition are established, which corresponds to the boundary conditions of type II with the value of heat flow rate equal to zero:

$$
\left.q\right|_{\text {bound. }}=0 \text {. }
$$




\section{Numerical study}

Calculation of temperature fields and heat flow rate in the studied structural elements are performed in Cartesian coordinate system with the use of ANSYS Mechanical APDL 17.0.

The calculation results for temperature fields in normal cross-section of the studied structures are presented in Figures 2-5.

Figure 2 shows the calculation results for temperature fields in the cross-section of a corner fragment for the set structural elements.

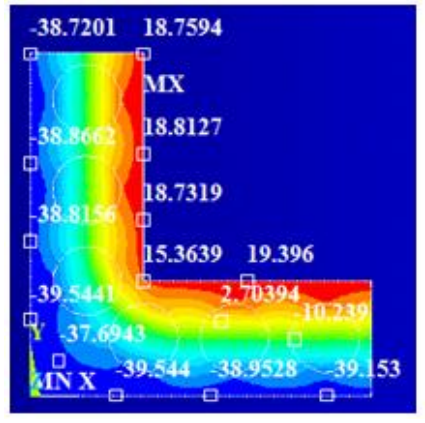

a)

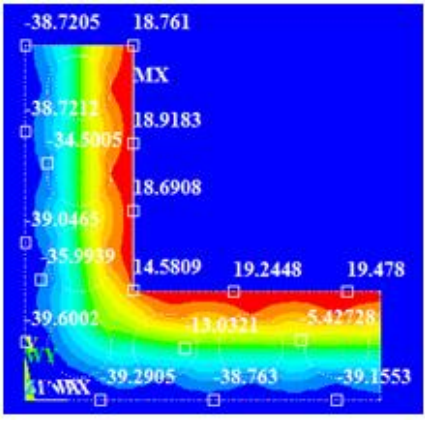

b)

Fig. 2. Behavior of temperature fields in structures: $a$ - wall structure produced according to variant $1 ; b$ - wall structure produced according to variant 2 .

The results of temperature fields calculation presented in Figure 2 show that temperature of the corner of the structure produced according to variant 1 is $0.78^{\circ} \mathrm{C}$ higher than that of the structure produced according the variant 2 . However, formation of condensate in the wall corner is excluded in both cases with $t_{\text {ind }}=+22{ }^{\circ} \mathrm{C}$ and relative humidity of indoor air $\varphi=$ $50 \%$, the dew point temperature being $t_{\circlearrowright}=+10,5^{\circ} \mathrm{C}$.

Figures 4 and 5 illustrate the calculation results for heat flow rate in the studied fragments of envelope structures.

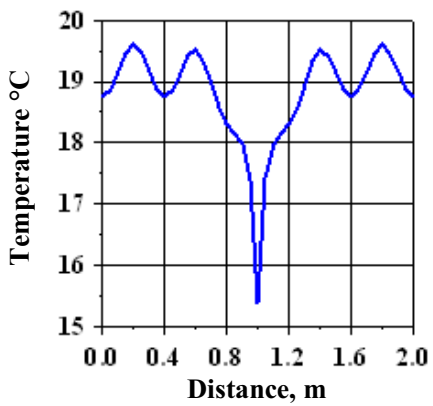

a)

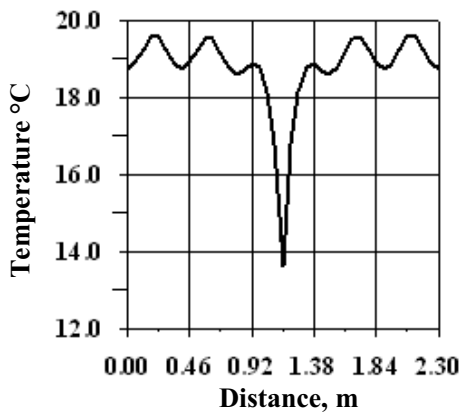

b)

Fig. 3. Temperature curve on the internal surface of the structure: $a$-wall structure produced according to variant $1 ; b-$ wall structure produced according to variant 2 . 


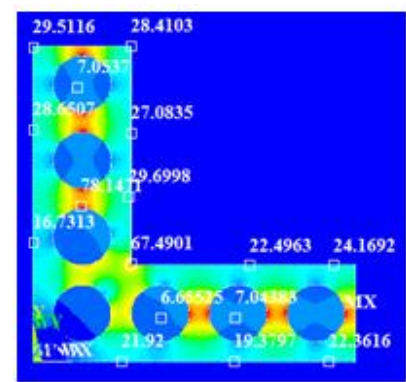

a)

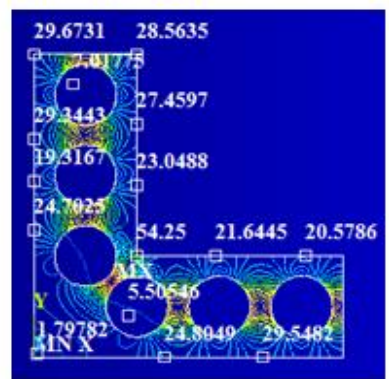

b)

Fig. 4. Distribution of heat flow rates in structures: $a$-wall structure produced according to variant 1 ; $b-$ wall structure produced according to variant 2 .

After analyzing Figures 4 and 5 one can conclude that the highest values of heat flow rates inside both types of structures are observed between the insulating fillers. For the structure produced according to variant 1 the maximum value of heat flow rate in the corner is $67.49 \mathrm{~W} / \mathrm{m}^{2}$, and for the structure of variant $2-54.25 \mathrm{~W} / \mathrm{m}^{2}$.

With the increase of thermal conductivity of lightweight aggregate concrete the temperature on the internal surface of external wall reduces, which causes the risk of condensate formation in the corner of the wall (Fig. 6). Thus, with thermal conductivity of lightweight aggregate concrete equal to $0.92 \mathrm{~W} /\left(\mathrm{m} \cdot{ }^{\circ} \mathrm{C}\right)$ the value of wall surface temperature is lower by the average value of 2.7 than that of the wall made of lightweight aggregate concrete with thermal conductivity of $0.41 \mathrm{~W} /\left(\mathrm{m} \cdot{ }^{\circ} \mathrm{C}\right)($ Fig. 6$)$.

In the corner of the lightweight aggregate concrete with thermal conductivity of $0.92 \mathrm{~W} /\left(\mathrm{m} \cdot{ }^{\circ} \mathrm{C}\right)$ the temperature value is $9.45{ }^{\circ} \mathrm{C}$, which is lower that the dew point temperature when $t_{\text {ind }}=+22{ }^{\circ} \mathrm{C}$ and relative humidity of internal air is $\varphi=50 \%$. One of the measures to increase the temperature in the corner is the use of heating cable [15]. In Figure 6, the curve 2 characterizes the temperature distribution on the internal surface of the wall with heating cable.

The performed calculations showed that when installing a heating cable with the power of $q_{v}=50 \mathrm{~W} / \mathrm{m}$ in the lightweight aggregate concrete with the thermal conductivity of $0.92 \mathrm{~W} /\left(\mathrm{m} \cdot{ }^{\circ} \mathrm{C}\right)$, the temperature in the corner increases up to $14{ }^{\circ} \mathrm{C}$ (Fig. 6). The cable with the specified power heats the structure up to the distance of about $0.3 \mathrm{~m}$ from the corner, further wall surface temperature does not change.

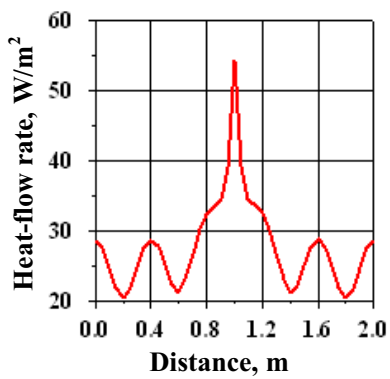

a)

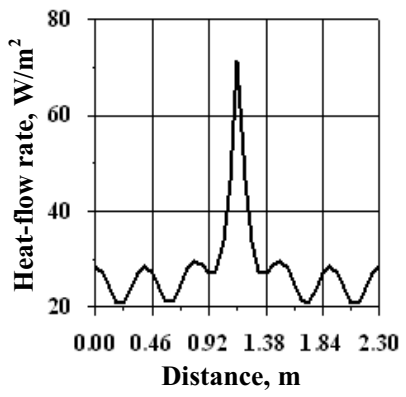

b)

Fig. 5. Distribution of heat flow rates in structures: $a$ - wall structure produced according to variant 1; $b$ - wall structure produced according to variant 2 . 


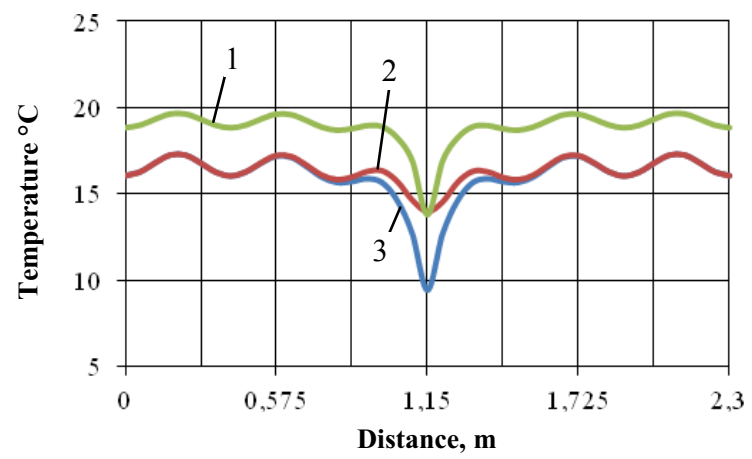

Fig. 6. Temperature curves for the internal surfaces of the structure produced according to variant 1: 1,3 - curves that characterize distribution of temperatures on the internal surface of the wall without heating cable; 2 - curves that characterize distribution of temperatures on the internal surface of the wall with heating cable; 1 - thermal conductivity of lightweight concrete is $0.41 \mathrm{~W} /\left(\mathrm{m} \cdot{ }^{\circ} \mathrm{C}\right) ; 2,3$ thermal conductivity of lightweight concrete is $0.92 \mathrm{~W} /\left(\mathrm{m} \cdot{ }^{\circ} \mathrm{C}\right)$.

\section{Conclusion}

The obtained research results show that mathematical modeling of thermal state of external envelope structures with the use of modern software packages enables to solve the problem of construction of buildings that satisfy ever increasing standard requirements regarding energy efficiency and to develop recommendations for design of such buildings.

For a more complex analysis of thermal protection properties of envelope structures other heat-stressed structural elements shall be studied except for corner fragments of buildings, such as joints between external wall, flooring plate and balcony plate, as well as window and door frames. It is also necessary to investigate thermal state of various heat-stressed elements under unstable conditions and extreme heat exchange conditions (intermittent heating, fluctuations of outdoor air temperature), and to study the issues of heat resistance.

The research was performed with the financial support of the Russian Foundation for Basic Research (project No. 16-48-700367 p_a).

\section{References}

1. D.M. Terent'ev, Energy-Savings, 3, 18-21 (2015) (in Russian)

2. I.A. Bashmakov, Problems of Economic Transition, 3, 75-98 (2016) (in Russian)

3. V.G. Gagarin, Vestnik MGSU, 3, 152-157 (2011) (in Russian)

4. Z. Wenxiao., Information of China Construction, 11, 135-138 (2007)

5. I.K. Savin, Kommunal'nyj kompleks Rossii [The utilities complex of Russia], 10, $12-$ 14 (2008) (in Russian)

6. L. Peng, Manual of Energy Efficiency in Buildings of China (Building Technology Publ., Beijing, 2007)

7. A.E. Kiryudcheva, V.V. Shishkina, D.V. Nemova, Construction of Unique Buildings and Structures, 5, 19-30 (2016) (in Russian)

8. M.I. Nizovcev, V.T. Belyj, A.N. Sterlyagov, Construction: new technologies - new equipment, 7, 38-42 (2016) (in Russian)

9. M.I. Nizovcev, A.N. Sterlyagov, Stroitel'stvo i rekonstrukcija [Construction and Reconstruction], 6, 112-119 (2016) (in Russian) 
10. F. Ascione, N. Bianco, F. de' Rossi, G.P. Vanoli, Proceedings of the 2012 Winter Simulation Conference, 567-581 (2012)

11. A.N. Kozlobrodov, E.A. Ivanova, Vestnik of TSUAB, 1, 133-139 (2016) (in Russian)

12. T.T. Zhang, Y.F. Tan, Y.Z. Li, Journal of Hunan University Natural Sciences, 42(7), 114-120 (2015)

13. A.N. Khutornoi, A.Ya. Kuzin, A.V. Kolesnikova, N.A. Tsvetkov, Bulletin of the Tomsk Polytechnic University, 309, 2, 188-192 (2006) (in Russian)

14. A.N. Khutornoi, A.V. Kolesnikova, N.A. Tsvetkov, A.Ya. Kuzin, RU Patent 49067 (2005) (in Russian)

15. N.D. Danilov, P.A. Fedotov, N.S. Akimova, D.F. Petrov, Eurasian Union of Sciences, 7, 160-162 (2015) (in Russian) 